\title{
Impact of the Intermittency of Photovoltaic Power Plants on the Frequency Management: Case of the Senegalese Electricity Grid
}

\author{
Mahamat Adoum Abdoulaye, Gabriel Jean Philippe Tevi, \\ Djicknoum Diouf, Amadou Seidou Maiga
}

LEITER, Laboratoire Electronique, Informatique, Télécommunication et Energies Renouvelables, Université Gaston Berger, Saint-Louis, Sénégal

Email: mahamatadoumabdoulaye1@gmail.com, tevi.gabriel-jean-philippe@ugb.edu.sn, djicknoum.diouf@ugb.edu.sn, amadou-seidou.maiga@ugb.edu.sn

How to cite this paper: Mahamat, A.A., Tevi, G.J.P., Diouf, D. and Maiga, A.S. (2020) Impact of the Intermittency of Photovoltaic Power Plants on the Frequency Management: Case of the Senegalese Electricity Grid. Journal of Power and Energy Engineering, 8, 55-70.

https://doi.org/10.4236/jpee.2020.87005

Received: May 27, 2020

Accepted: July 28, 2020

Published: July 31, 2020

Copyright $\odot 2020$ by author(s) and Scientific Research Publishing Inc. This work is licensed under the Creative Commons Attribution International License (CC BY 4.0).

http://creativecommons.org/licenses/by/4.0/

\begin{abstract}
This paper investigates the impact of the intermittency of the photovoltaic (PV) power plants on the electric grid frequency management and the consequences that can occur. To meet these purposes, three years data of the Senegalese grid frequency are used, combined with three PV power plants data since their starting-up. Using these data, we analyzed two days of heavily disturbed operation of the Senegalese grid in order to emphasize the real impact of the presence of PV power plants on the electrical grid. Our study has highlighted that how the intermittency of photovoltaic power plants affects frequency management. It obviously appears that the PV production curves follow the irradiation variations. Instantaneous variations of PV production make it difficult to manage the grid frequency leading to more frequent load shedding as we have shown with the data after the commissioning of the PV power plants. We also estimate the power then energy losses during the load shedding induced by the PV integration on the power grid by comparing a period corresponding to one month before (February 2017) and one month after (February 2018) the integration of variable PV production.
\end{abstract}

\section{Keywords}

Intermittency, Frequency Fluctuation, Energy Loss, Power Loss, Fluctuating Power

\section{Introduction}

Globally most of the power grids are now changing towards an integration of 
renewable energies (RE) due to many environmental reasons such as the global warming and the fossil fuel resources which are drastically decreasing. To face these challenges, RE electrical productions, like photovoltaic (PV) systems installed, are being connected to the grid.

Even though there are some small standalone PV generators in rural areas, especially in Senegal, located in West Africa [1] [2].

In the literature, we have Hernandez et al. who focused on the study of the impact of high PV penetration on feeders in Spain and in Finland [1]. They investigated more on the comparison between the effects of the PV integration on rural and urban feeders. Ali et al. also made an investigation on the occurrence of the overvoltage due also to the high penetration level of the grid connected PV system on the UK residential low voltage distribution [3]. In [4] [5] [6], authors focused on how parameters can be defined to evaluate in one case the grid weakness in Niger and in the second case, the PV penetration impact on the electrical grid of Burkina Faso. The authors in [2] [7] [8] [9] have made a review on the technical impacts that grid connected PV systems have. One of the outputs that they highlighted is that depending on the power production of the plants (small, intermediate and large), different levels of consequences on the grid can result.

The intermittent nature of the solar energy source imposes constraints in terms of the stability of the electricity grid. Indeed, the penetration rate in correlation with the load reductions represents a major challenge for the proper functioning of the grid. Thus, with the integration of renewable energy sources, variations in the production of PV power plants exacerbated by the drop in demand cause fluctuations in the frequency of the grid and affect the quality and continuity of service.

As grid-connected systems are recently making a breakthrough in Senegal, no study at all was done before on how the PV plants' production is behaving on the national grid.

In this work, we will make a state of art and challenges of the electricity supply in Senegal, then the impact of the PV power plants on the grid frequency management. And finally, we will make a detailed analysis of the behavior of PV power plants on the power grid to show the influence of the integration of PV power plants on the grid frequency management.

\section{Electricity in Senegal: Situation and Challenges}

The national Senegalese electrical grid is divided into two (2) main parts: An interconnected grid with other countries (Mali, Mauritania and Gambia) and an internally connected grid. These parts of grid are managed by the national electricity company named SENELEC. Its installed capacity of intermittent RE power plants (solar photovoltaic and wind) increased between the early 2014 to the end 2019 from $2 \mathrm{MWp}$ to $209 \mathrm{MWp}$ with the commissioning of eight (8) PV power plants (159 MWp) and one wind power plant (50 MW).

The mix energy on the national grid started up in 2016 with the inauguration of the PV power plants of Bokhol (20 MWp) and Malicounda (22 MWp), those of 
Santhiou Mékhé (30 MWp) and Tenmérina (30 MWp) in 2017, Kahone (20 MWp) and Sakal (20 MWp) in 2018, and Diass (15 MWp) in 2019. This trend show the rapid growing in solar PV power plans connected to the grid as shown in "Figure 1".

This fast growth in Senegal can be explained by the cost reductions linked to technological advances, economies of scale in production and innovations in financing, as well as the policy that the Senegalese government has implemented on the promotion of renewable energies since 2013.

The recent status of the total installed capacity of PV and wind power plants represents a rate of integration of RE of $21 \%$ of the total power of the SENELEC production fleet "Figure 2". But this rate varies between 21 and $26 \%$ depending on the time of year and the time of day. In this renewable part, only $17 \%$ comes from the solar PV (159 MWp).

The particularity of this source of production is that solar PV is only available during the daylight which induces a withdrawal of a significant part of production during the night when the consumption peak is observed.

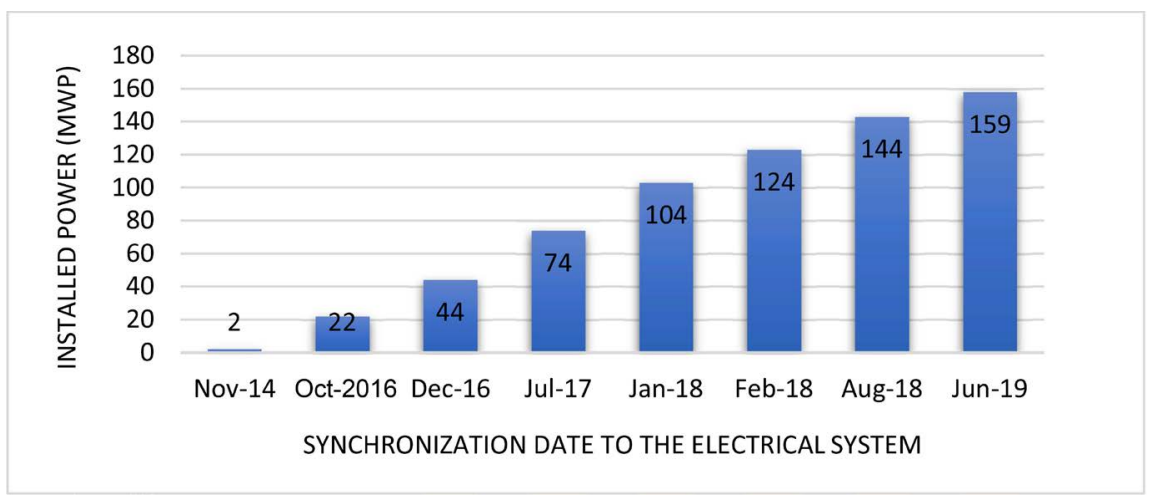

Figure 1. Evolution of the installed capacity of grid connected solar PV power plants from 2014 to 2019 in Senegal.

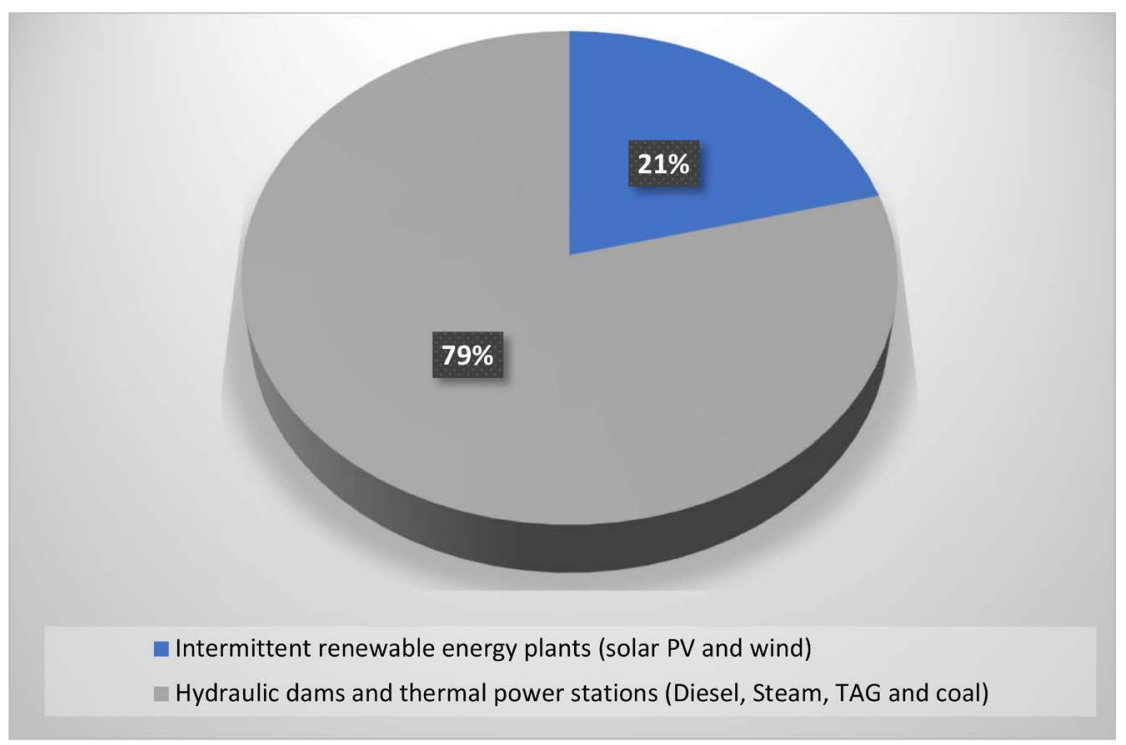

Figure 2. Proportion of SENELEC electricity production from intermittent renewable energy plants compared to other energy sources. 
The annual Global Horizontal Irradiation (GHI) average in Senegal varies from $2050 \mathrm{kWh} / \mathrm{m}^{2}$.year in the south region, Ziguinchor, to $2200 \mathrm{kWh} / \mathrm{m}^{2}$.year in the north hence advantageous sun conditions that allow the development of PV projects.

Nevertheless, the main challenges for the photovoltaic solar energy are "Figure 3": the Non-controllable variability (a) because it is weather dependent, the Partial unpredictability (b) due to inaccurate weather forecasts and the Geographical dependence (Irregular geographical distribution) (c).
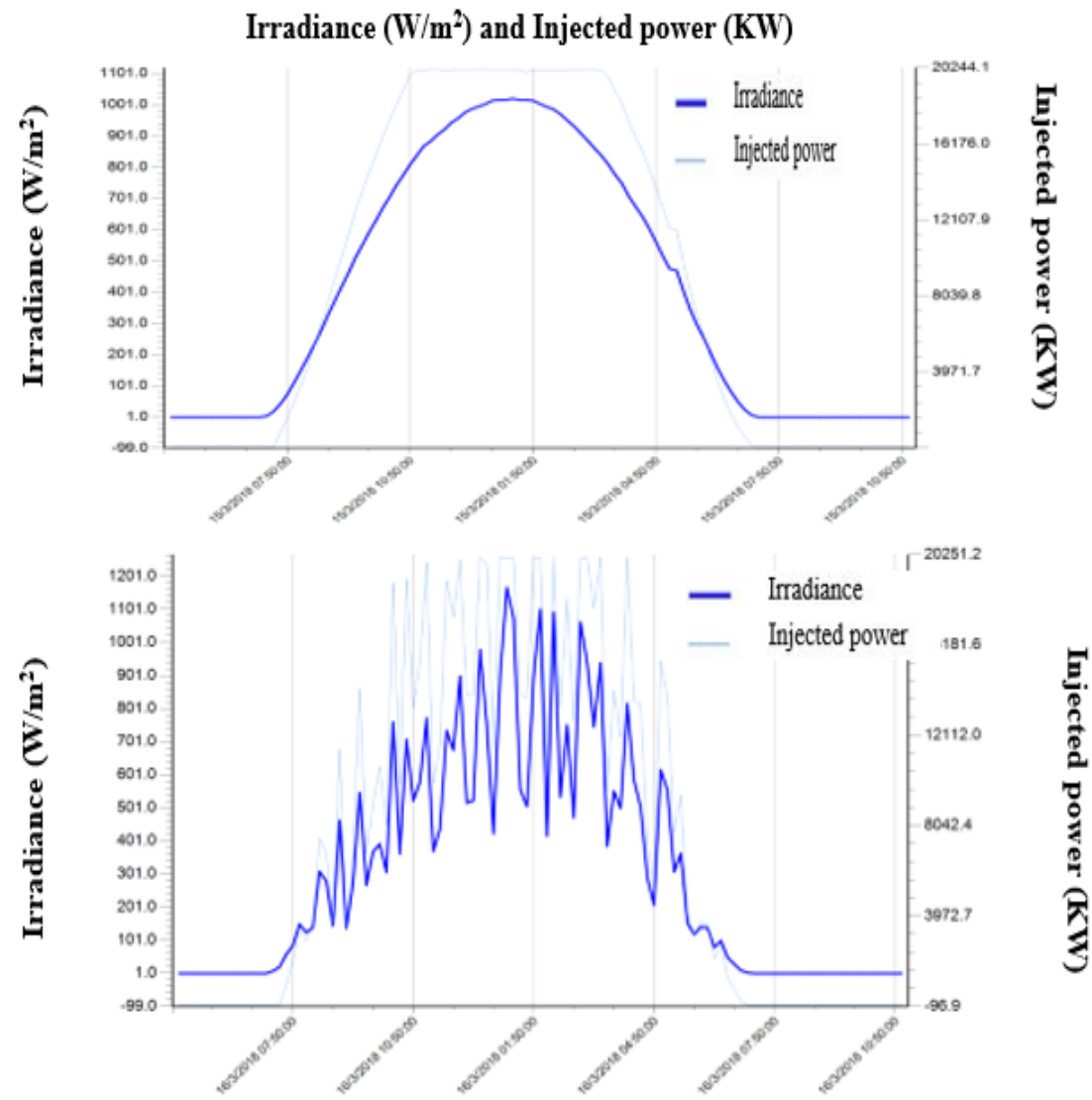

(a)

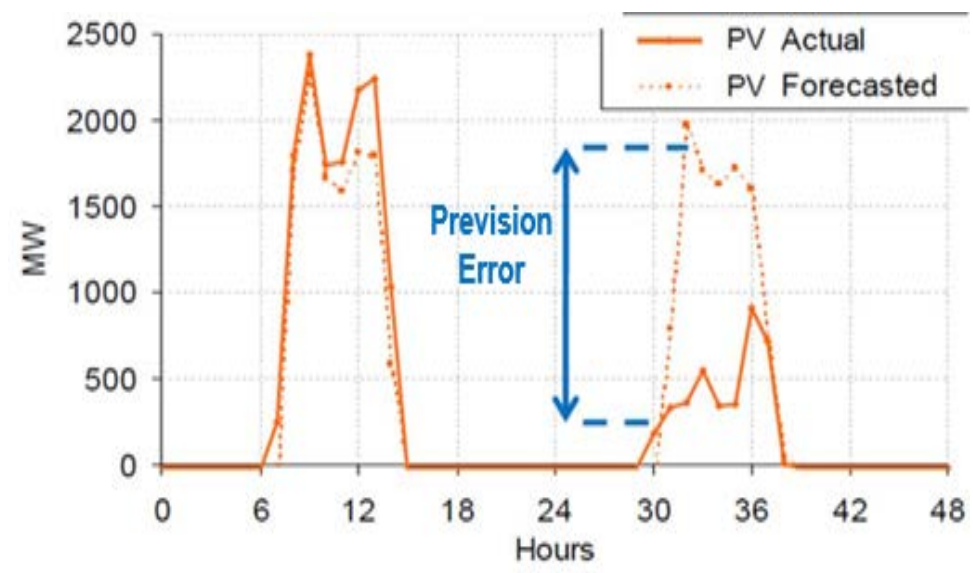

(b) 


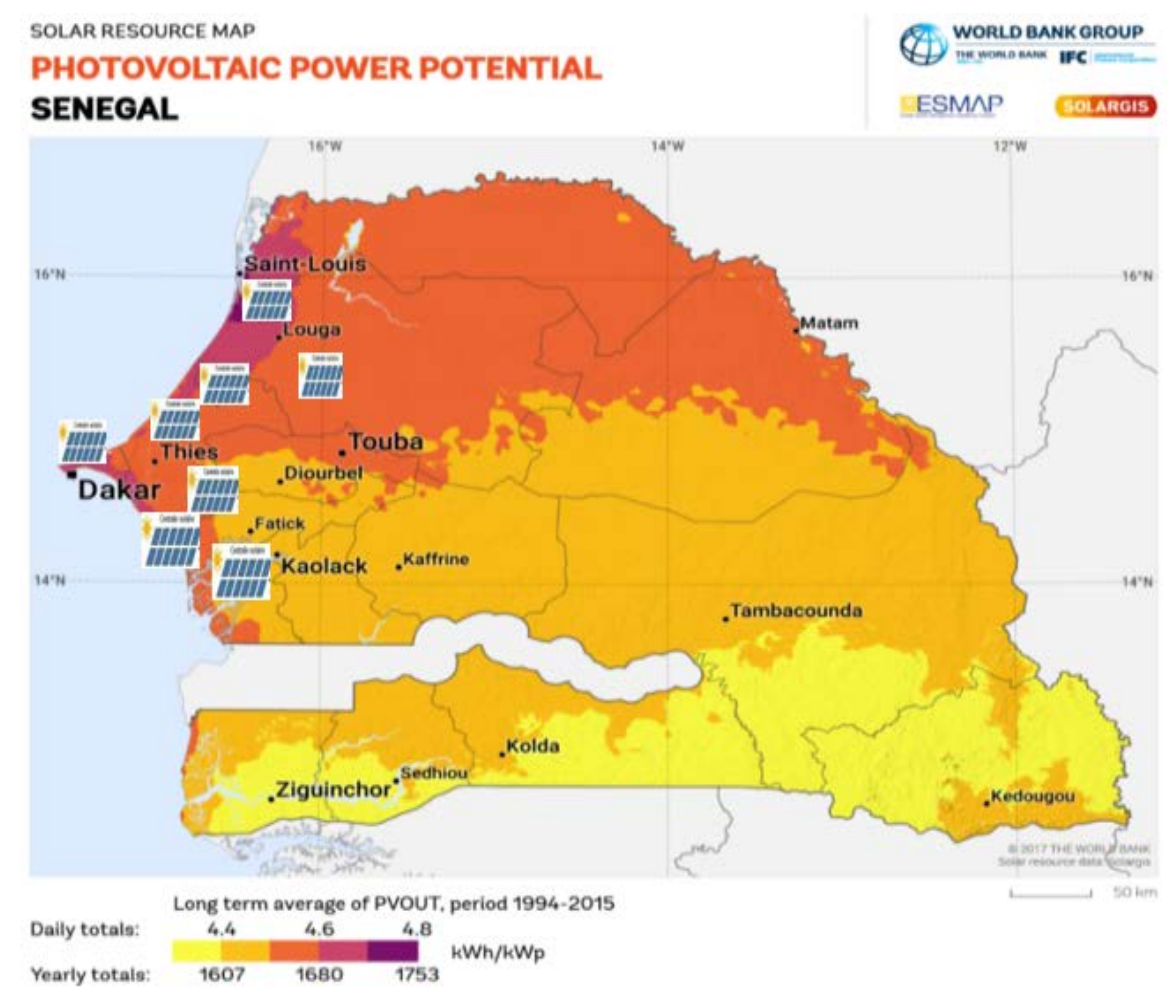

(c)

Figure 3. The main challenges for the photovoltaic solar energy. (a) Example of Non-controllable variability of PV Power Plant (Irradiance and Injected power of Mékhé PV power plant for the day of 15-03-2018 (above) and the day of 16-03-2018); (b) Example of Partial unpredictability of PV Power Plant; (c) Example of Geographical dependence of PV Power Plant (Senegalese photovoltaic power potential and the installed PV power plants).

As clearly describe by [10] [11] [12], managing the integration of the RE, particularly the solar PV, on the national grid, need to take into account in the strategy, the daily and seasonal changes in the electrical consumption balance; knowing the PV is environmental-dependent. Thus, the intermittent nature of the solar energy source imposes constraints in terms of the stability of the electricity grid. Indeed, the penetration rate, in correlation with load fall represents a major challenge for the correct operation of the grid. Thus, with the integration of renewable energy sources, variations in PV power plant production exacerbated by declining demand lead to excursions (fluctuations) in grid frequency and affect the quality and continuity of the service. While PV power generation is growing rapidly, we noticed that no intermittency management strategy for the integration of these productions has been clearly planned by the national electricity supplier. In fact, given the part of these energies which is beginning to be more and more remarkable, difficulties started to be felt in the operation of this Senegalese electrical grid. Considering the number of RE projects that are planned, if no action is taken, the stability of the grid may be threatened starting by the RE suppliers [1]. According to [2] [7] and as the present study will show, 
the instability can go worse. For this work, operating data are analyzed to highlight the impact of the intermittency of PV power plants. Different levels and stages can be affected [1]-[7] but our study focuses on the frequency management of the power system. It is essential to understand that the power grid frequency is a non-local physical quantity meaning that a disturbance in frequency in one supply point of the grid due by the PV production, may impact a large part of, if not all, the Senegalese power system [2] [9].

\section{Impact on the Frequency}

In this part and in the following parts the methodology adopted is described, the results and discussions are made progressively with each analysis.

For the analysis of the impact of the PV power plants on the frequency, we investigated three years data of the Senegalese grid frequency (2016, 2017 and 2018), combined with the data of three PV power plants (the power produced and injected into the grid, the irradiation and the temperature of modules) since their starting-up.

The methodology for the selection of the months and the operating days is:

- Firstly, we look in the data for grid disturbances and inconsistencies before and after integrating PV power plants into the grid;

- Then, we seek specific participation on the disturbances of PV power plants on the grid;

- Finally, we correlate the data that we had to continue to do our analysis.

We emphasized all the days where we had a strong production variation of the PV power plants and in the same time load shedding in the electric grid due to frequency instability.

Thus, the $3 \mathrm{PV}$ power plants were chosen for the following reasons:

- The BOKHOL PV plant is the first largest PV plant connected to the $30 \mathrm{KV}$ substation (Dagana $30 \mathrm{KV}$ substation). It has an installed capacity of $20 \mathrm{MWp}$.

- The TENMERINA and SANTHIOU MEKHE PV power plants have the same configuration, the same installed power (30 MWp each) and they inject at the same connection point which is the MEKHE $90 \mathrm{KV}$ substation. This is the greatest power injected of all the PV plants currently connected to the Senegalese grid.

- Among the eight (8) PV power plants currently being injected into the Senegalese grid, five (5) are connected to the $30 \mathrm{KV}$ substation including BOKHOL and the two (2) to the $90 \mathrm{KV}$ substation (TENMERINA and SANTHIOU MEKHE).

- So, by analyzing the impact of the intermittency of these three (3) PV power plants (BOKHOL, TENMERINA and SANTHIOU MEKHE), we are dealing with the case of all PV power plants currently being injected into the Senegalese grid.

Based on the analysis of data by the methodology described above, we chose the day of November $26^{\text {th }}, 2017$ and the day of December $17^{\text {th }}, 2017$ to carry out our analysis in order to show the impact of the intermittence of PV power plants on the grid. 
As a reminder, the Senegalese grid frequency was severely disrupted during those two days of operation.

For the day of November $26^{\text {th }}, 2017$, two (2) PV plants (Santhiou Mékhé and Tenmérina) are examined to analyze the bearing of the intermittency on the frequency management and then for the day of December 17 $7^{\text {th }}, 2017$ we increased the penetration rate of PV plants in the power grid by considering one more PV plant (Bokhol).

Normally, when the available energy of national electric company SENEGALESE is not enough, the PV plants have to feed in the grid; and this generally results in a perturbation on the frequency of the grid. When the frequency goes beyond the fixed values of the interconnected grid regulation (under $49.7 \mathrm{~Hz}$ or above $50.3 \mathrm{~Hz}$ ), a power shed is made. There are automatic shedding and manual shedding.

\subsection{Analysis of the Day of November $26^{\text {th }}, 2017$ Data}

The interconnected power grid operation is marked by a load reduction, which corresponds to $391 \mathrm{MW}$ on average between 8:00 am and 04:00 pm, favoring an increase in the share of PV power plants in the energy produced. Thus, this situation has been characterized by fluctuations in grid frequency due to variations in the production of PV power plants. In fact, the Santhiou Mékhé $\left(\mathrm{PV}_{1}\right)$ power station recorded a load curve marked by drastic variations in power delivered to the national electricity company as shown in "Figure 4". These variations are deeper from 12:32 to 12:38 and from 13:51 to 15:02 "Figure 4" resulting in a manual load shedding of $6 \mathrm{MW}$ from 15:00 to 15:03 as shown in "Figure 5" and a presence time on the $49.7 \mathrm{~Hz}$ and $50.3 \mathrm{~Hz}$ range of $58.12 \%$. The Tenmérina $\left(\mathrm{PV}_{2}\right)$ power plant did not record much fluctuation on that day.

As the electrical energy produced by a PV plant depends on the temperature and the solar irradiation, these parameters can also be the cause of the load variations of

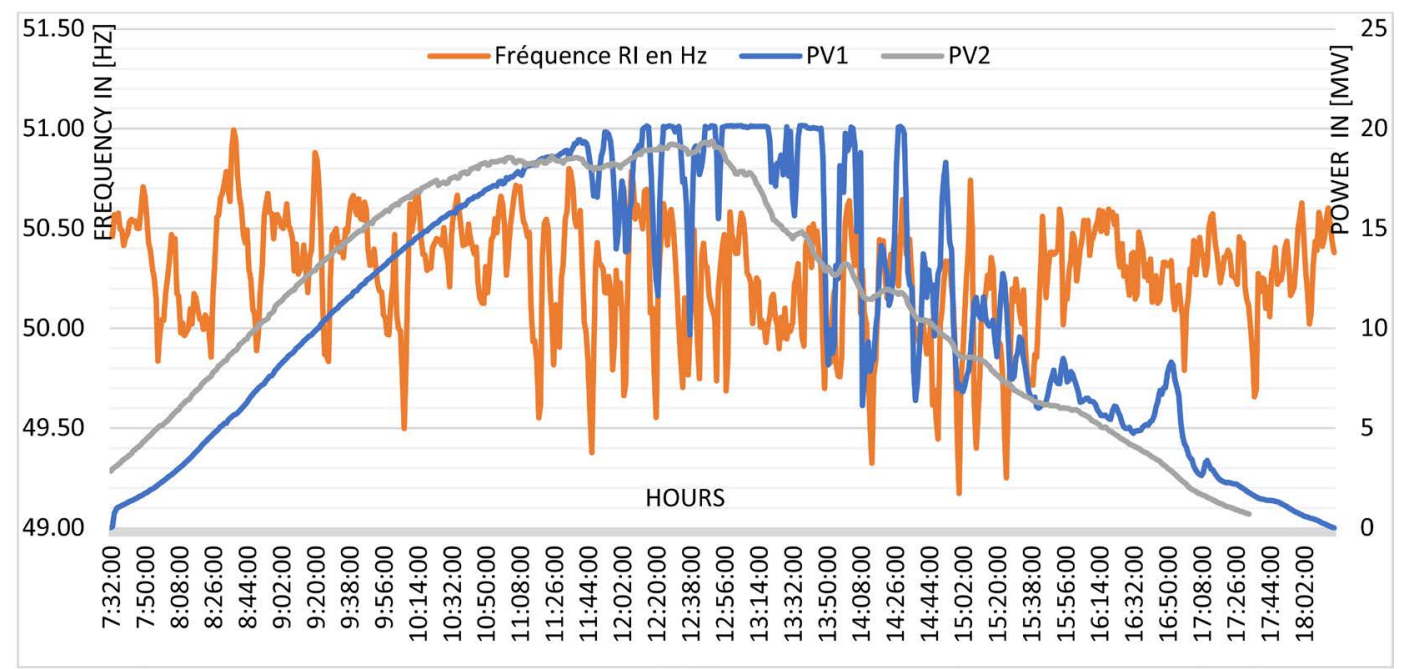

Figure 4. Power statement of the Santhiou Mékhé $\left(\mathrm{PV}_{1}\right)$ and Tenmerina $\left(\mathrm{PV}_{2}\right) \mathrm{PV}$ stations and the frequency during November $26^{\text {th }}, 2017$. 


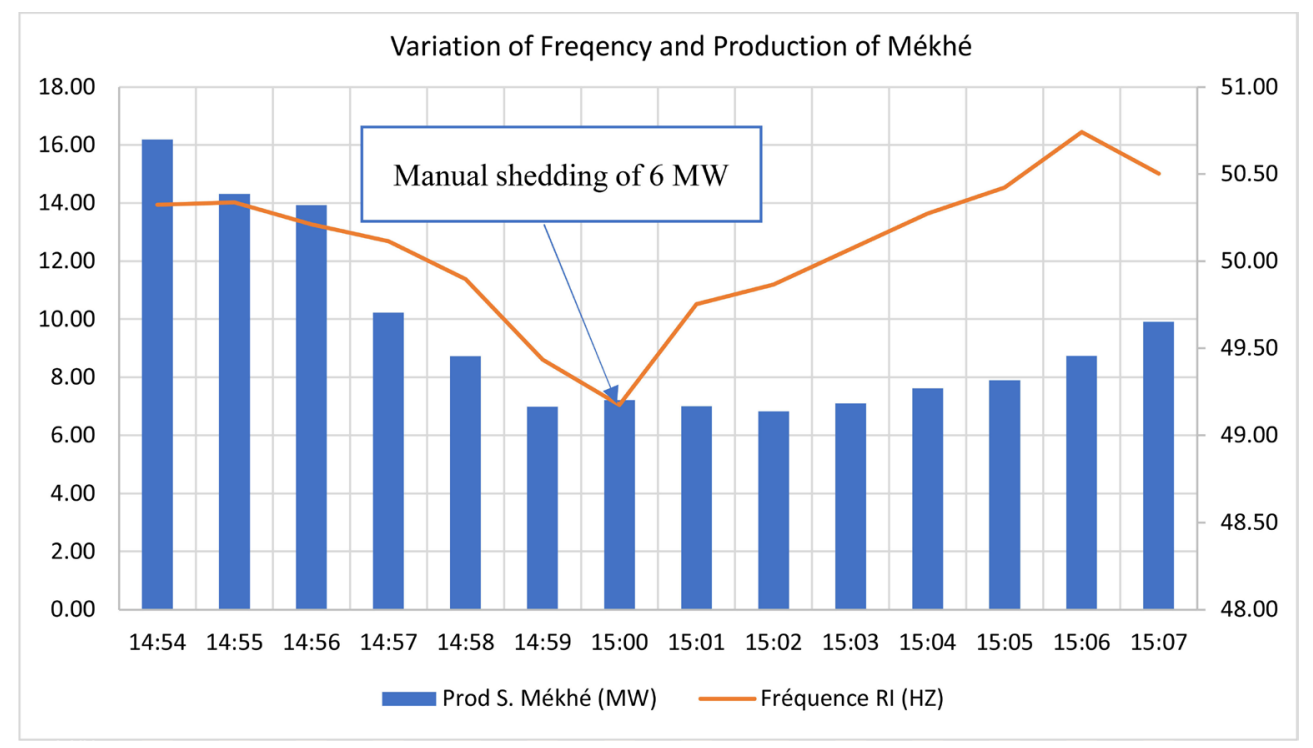

Figure 5. Frequency RI and the production of the PV power plant of Santhiou Mékhé between $14: 54$ and $15: 13$.

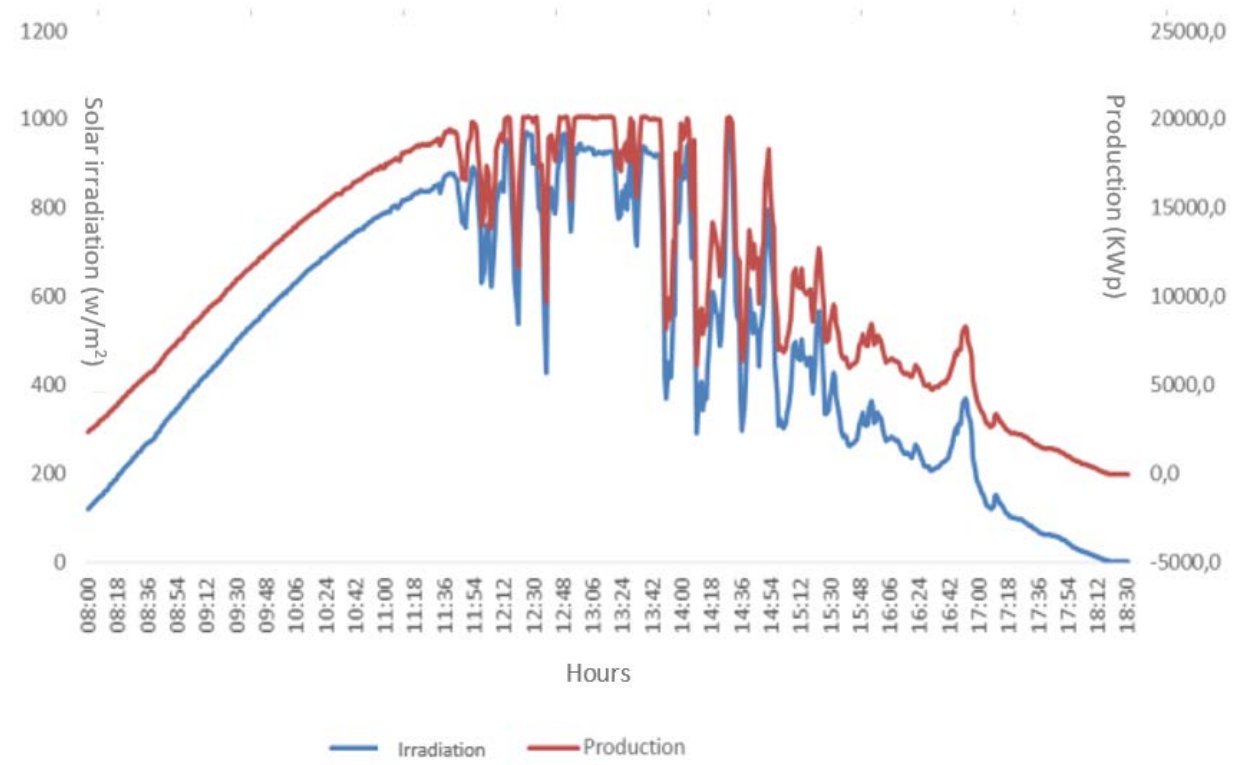

Figure 6. Irradiation and PV production of santhiou Mékhé's plant on November $26^{\text {th }}, 2017$.

the power plant of Santhiou Mékhé noticed previously. Thus, we performed the analysis of the parameters of the solar irradiation to emphasize the real origin of these power fluctuations.

"Figure 6" shows the profile of solar irradiation and the output production of the Santhiou Mékhé power plant on November $26^{\text {th }}, 2017$.

Following the observation of "Figure 6", we can notice that the solar irradiation curve has the same characteristics as that of the power produced by the plant and delivered to the national electricity company. Hence a decrease of the irradiation automatically results in a decrease of the power produced by the plant. Drastic irradiation variations happened between 11:36 and 17:00 and in 
particular during the period of manual shedding. We can conclude that the disturbances caused by the PV power station of Santhiou Mékhé during November $26^{\text {th }}, 2017$ were triggered by variations of solar irradiation.

\subsection{Analysis of the Day of December $17^{\text {th }}, 2017$ Data}

As we previously said it, to continue with the analysis, for the second day considered, the penetration rate of the PV power plants in the power grid has been increased by including now three (3) PV power plants (Santhiou Mékhé, Tenmérina and Bokhol). The operation of the electric system of the interconnected grid on December $17^{\text {th }}, 2017$ is marked by a load reduction. This reduction has an average of $318 \mathrm{MW}$ between 8:00 and 16:00, with a maximum of $331 \mathrm{MW}$ at 16:00. It resulted in an increase in the share of PV plants in the energy produced. Thus, this situation is characterized by fluctuations in the frequency of the grid and a presence time over the range allowed by the interconnected grid regulation $(49.7 \mathrm{~Hz}$ and $50.3 \mathrm{~Hz}$ ), of $51.88 \%$ due to disparities in the power produced by the PV plants. "Figure 7" illustrates the frequency fluctuations during that day.

Considering "Figure 7", twelve (12) frequency deviations were emphasized, seven (7) load shedding operations were performed including three (3) automatic load shedding of $1^{\text {st }}$ stage. The details of these load sheddings are presented in "Table 1".

As we can see in "Table 1", the first stage load shedding is on average $42 \mathrm{MW}$ for eight (8) minutes per interruption approximately and the manual load shedding is $8.5 \mathrm{MW}$ for seven (7) minutes per outage on average. By using the data gathered, we plotted the load curves of the PV plants and focused on the loadshedding times in order to identify their impacts on these service interruptions. On that account, the load curves of the Tenmerina and Santhiou MékhéPV plants are shown in "Figure 8".

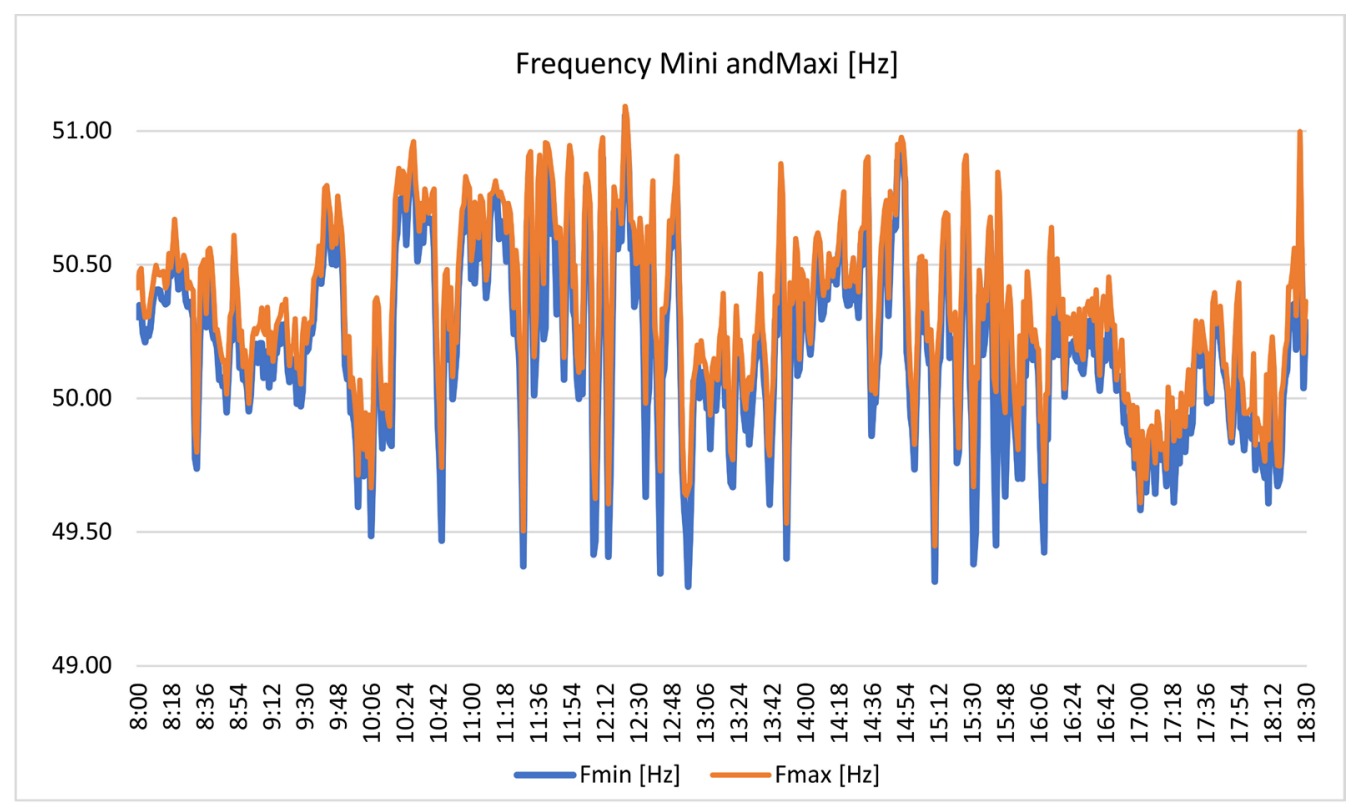

Figure 7. Statement of the minimum and maximum frequency during December 17 $7^{\text {th }}, 2017$ between 08:00 and 18:30. 
Table 1. Electrical shedding made on December $17^{\text {th }}$, 2017 between 12:35 and 16:13.

\begin{tabular}{cccc}
\hline \multirow{2}{*}{ Type of load shedding } & \multicolumn{3}{c}{ Electrical shedding } \\
\cline { 2 - 4 } & Start time & End time & Power shed [MW] \\
\hline 1st stage & $12: 35$ & $12: 44$ & 52.8 \\
Manual & $12: 42$ & $12: 43$ & 3.8 \\
Manual & $15: 32$ & $15: 53$ & 5 \\
Manual & $15: 44$ & $15: 46$ & 5 \\
1st stage & $15: 44$ & $15: 46$ & 34.2 \\
1st stage & $15: 48$ & $16: 03$ & 38 \\
Manual & $16: 08$ & $16: 13$ & 20 \\
\hline
\end{tabular}

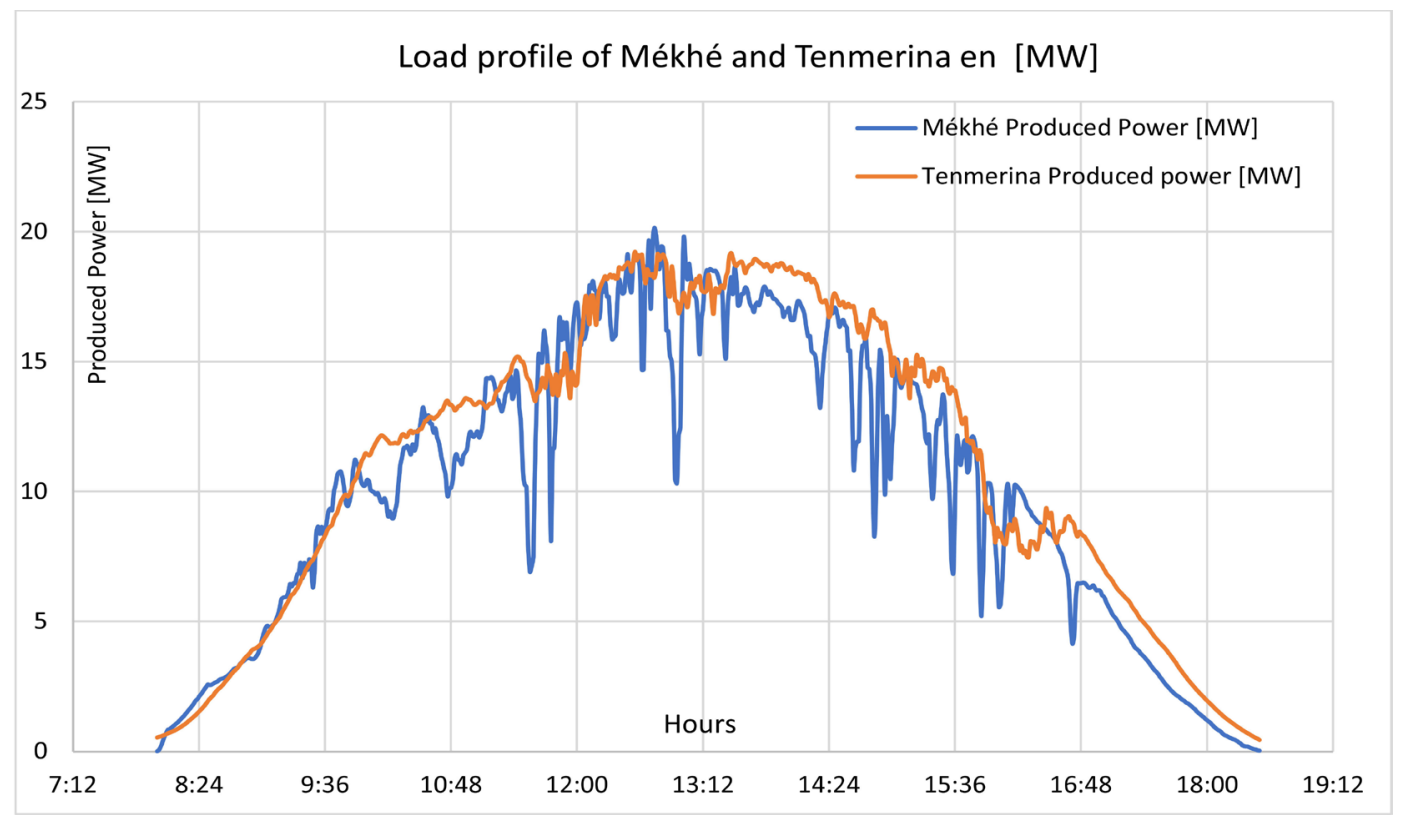

Figure 8. Load profile of the Santhiou Mékhé and Tenmérina PV plants.

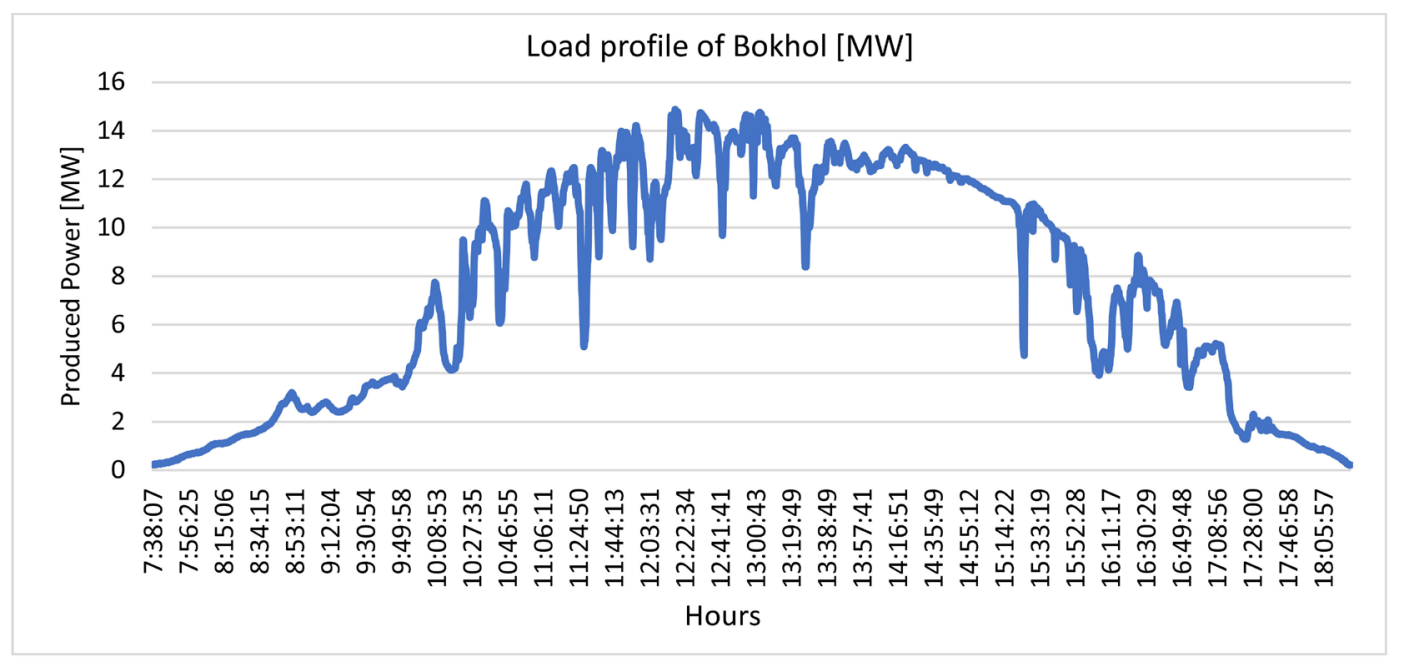

Figure 9. Power reading of the Bokhol PV plant between 07:38 and 18:03 during December 17 2017. 


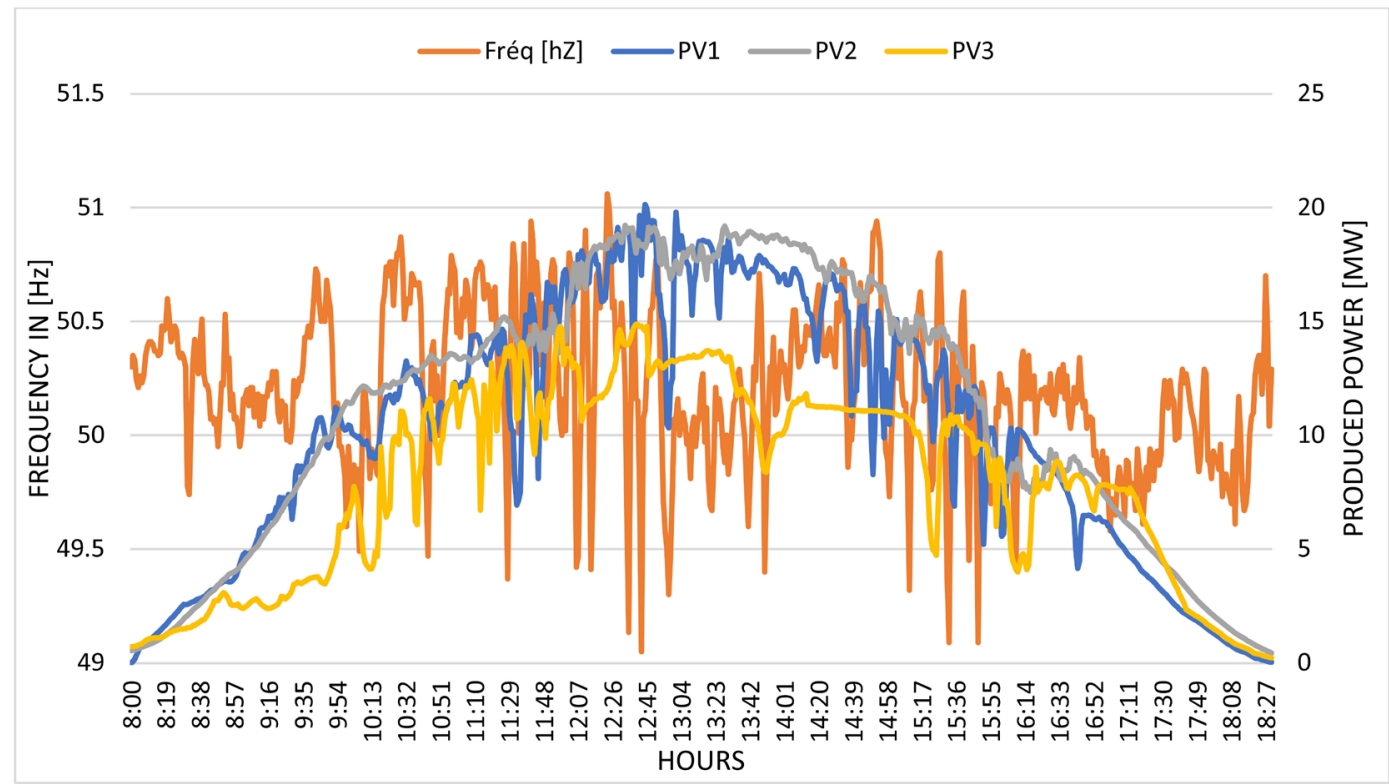

Figure 10. PV Plant Power and Frequency Readings on December 17 ${ }^{\text {th }}, 2017$

By analyzing these curves "Figure 8", it can be seen that the Santhiou Mékhé power station recorded a load curve characterized by harsh variations in power delivered to the national electricity company. These variations are deeper between 11:34 and 11:52, between 12:58 and 13:18 and between 14:42 and 16:10.

However, the Tenmerina plant was not subject to these variations. As mention at the beginning, the load profile of the Bokhol PV power plant is added to the analysis of December $17^{\text {th }} 2017$; the curves are shown in "Figure 9" coming next: From this curve shown in "Figure 9", we noticed significant load fluctuations. These excursions are more accentuated between 10:08 and 13:10 and between 15:25 and 16:54. In "Figure 10", we illustrate the frequency fluctuations and load variations of the $3 \mathrm{PV}$ power plants during the day of $17^{\text {th }}$ December 2017.

\section{Analysis of the Different Times of Load Shedding on December 17th, 2017}

\subsection{The First Two Load Shedding}

The first frequency-metric load shedding recorded is a $1^{\text {st }}$ stage of $52.8 \mathrm{MW}$ at $12: 35 \mathrm{pm}$ while the second is a manual load shedding of $3.8 \mathrm{MW}$ at 12:42 pm. "Figure 11" details the load readings of the PV power plants and the frequency between 12:30 and 12:45. In "Figure 12", it can be seen that the PV power plants had no impact on the occurrence of the first stage load shedding at 12:35. While the $4 \mathrm{MW}$ and 2.42 MW load decreases between 12:40 and 12:42 respectively from Bokhol and Santhiou Mékhé impacted the onset of the 3.8 MW manual shedding. We can clearly see in "Figure 12" that the manual load shedding is caused by the load reduction of the Bokhol and Santiou Mékhé power plants. We will analyze the causes of this fluctuation in the coming paragraphs dedicated to the causes of disturbances. 


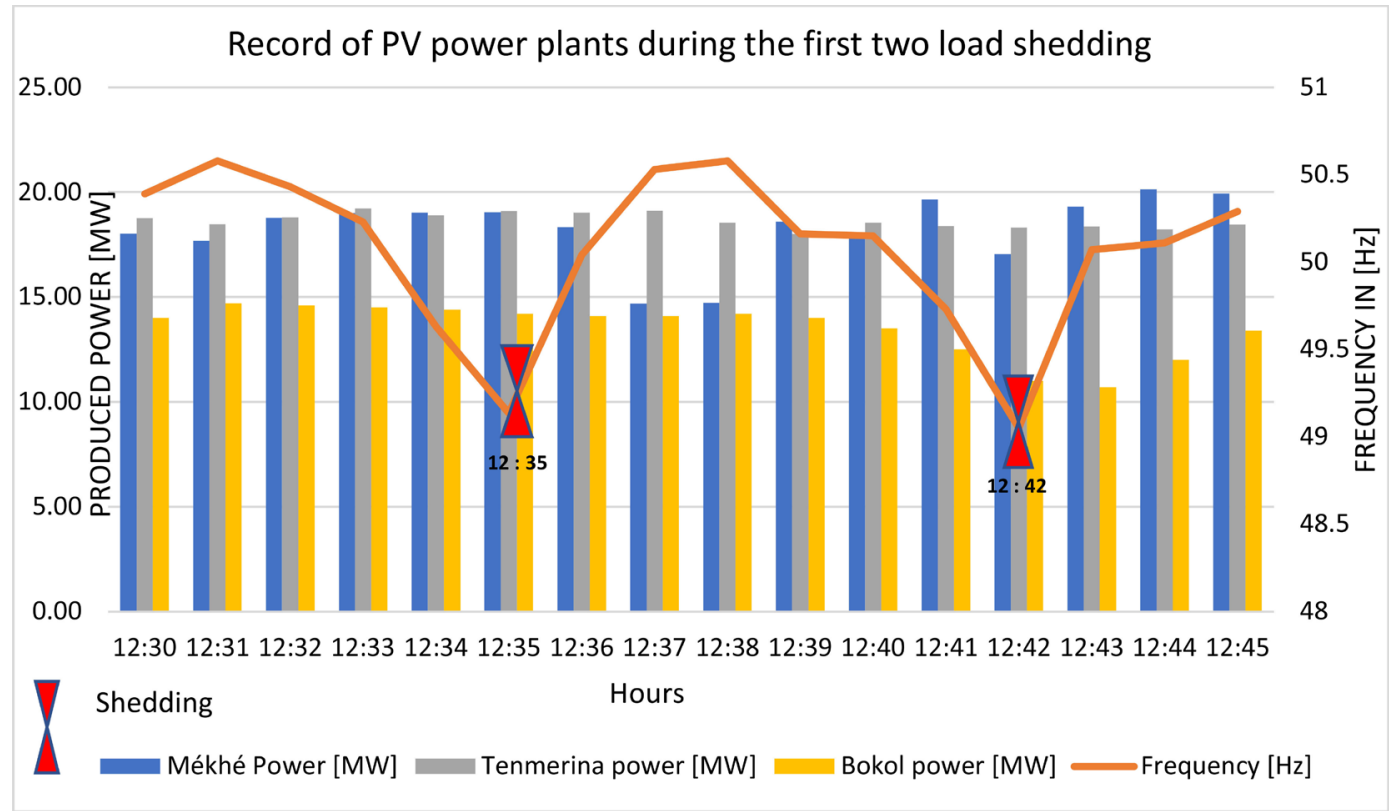

Figure 11. Load profiles of the three PV plants and the frequency at the time of the first two load sheddings.

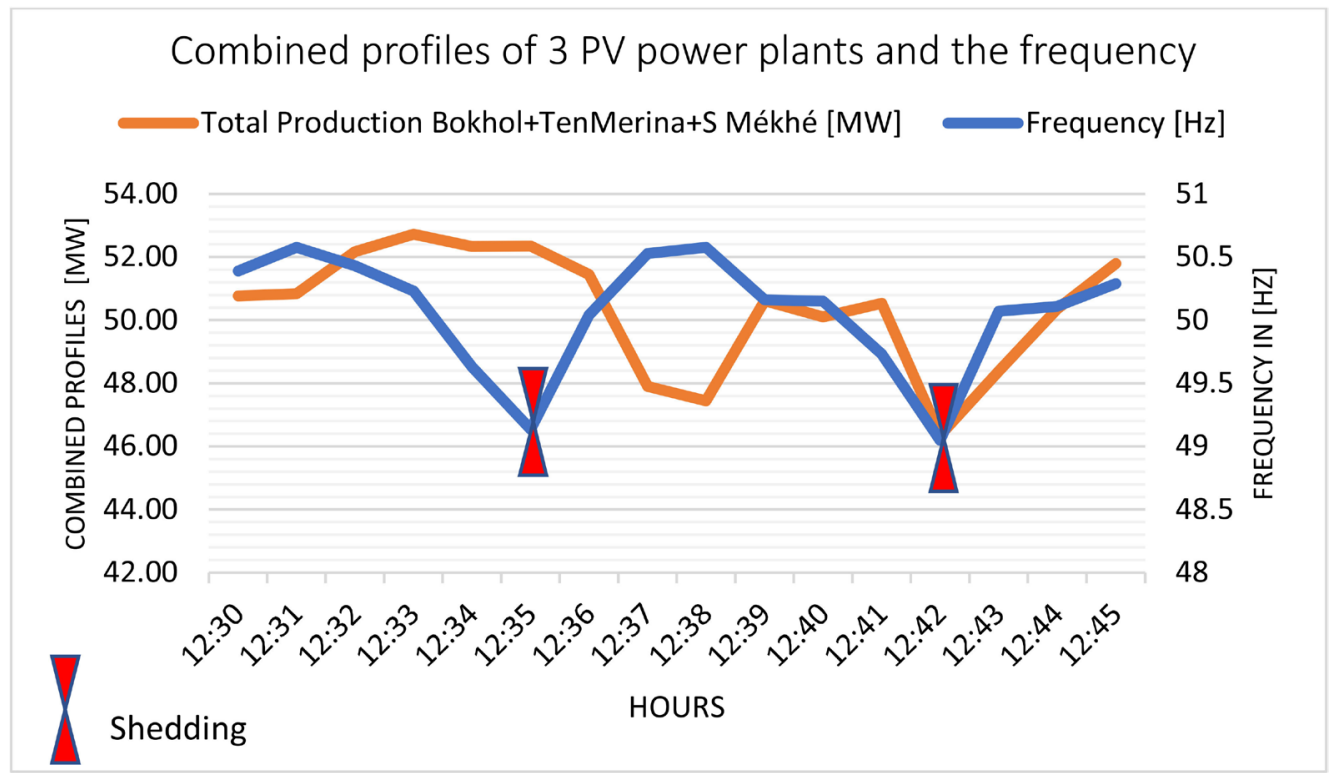

Figure 12. Combined profiles of the three PV power plants and frequency during the first two load shedding.

\subsection{The Others Load Sheddings}

The others load sheddings occurred between 3:25 pm and 4:08 pm. In "Figure 13", we noticed the $5 \mathrm{MW}$ drop in two minutes of the PV plants which contributed to the occurrence of the manual shedding of $5 \mathrm{MW}$ at 3:32 pm. Also, the decrease in production of $3 \mathrm{MW}$ PV power plants between 16:05 and 16:08 has also contributed to the advent of the manual load shedding of $20 \mathrm{MW}$ at 16:08. Concerning the first stage load shedding at 15:42 and 15:44, an overall load reduction of $3 \mathrm{MW}$ for two (2) minutes just before the load shedding was noted. 


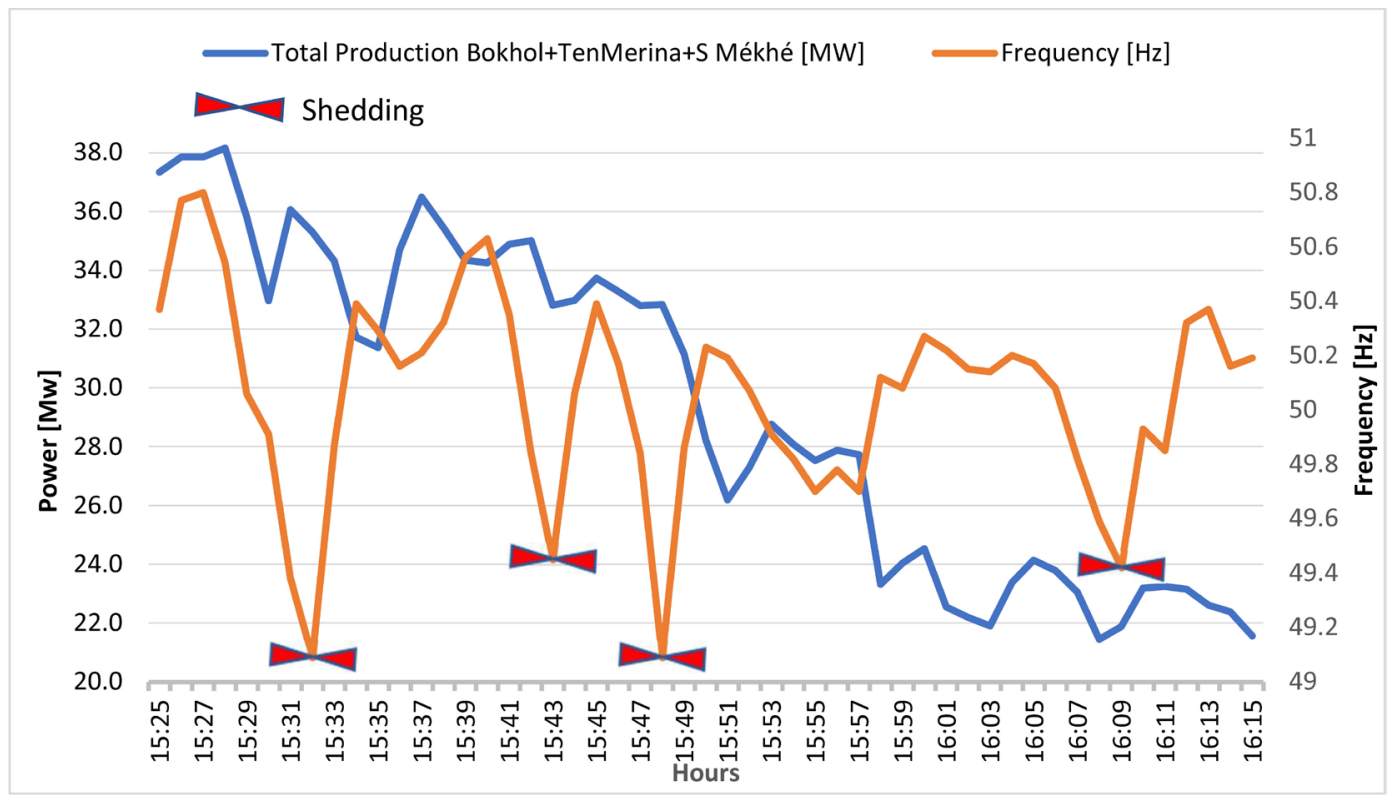

Figure 13. Combined profiles of the three PV plants and frequency between 15:25 and 16:15.

\subsection{Power and Energy Lost on the Grid}

We analyzed the behavior of the power grid and the PV power plants by comparing a period corresponding to one month before and one month after connection of the PV plants to the national electric grid in order to determine the energy lost. As mentioned here, for this analysis, we investigated three years data of the Senegalese grid frequency $(2016,2017$ and 2018) and the PV power plants data since their start-up (the power produced and injected into the grid, the irradiation and temperature of modules). Thus, we have chosen two months, February 2017 and February 2018 corresponding respectively to a month before and a month after the connection of Santhiou Mékhé and Tenmérina PV plants to the grid. During the month of February 2018, we found that the plant of Santhiou Mékhé participated in the disturbances of the electricity grid.

"Table 2 and Table 3" represent the number of the power grid disturbances caused by frequency variations respectively in February 2017 and February 2018.

After analyzing these two tables, it came out that the Senegalese electricity grid has suffered more manual and automatic load shedding after the connection of the PV power plants, than before. Another remark is that the number of manual shedding has increased from 0 in February 2017 to 7 in February 2018. The number of automatic shedding also has increased from 13 in February 2017 to 24 in February 2018. The manual load shedding capacity increased from 0 MW in February 2017 to 48 MW in February 2018. The power of automatic load shedding has also increased from 502.1 MW in February 2017 to $955 \mathrm{MW}$ in February 2018. Among the 31 load shedding operations of February 2018, the Mékhé PV power stations caused 3 power outages, including 1 automatic and 2 manuals. We note that before the connection of the PV power plants (Santhiou Mékhé and Tenmérina) i.e. February 2017, the frequency load shedding capacity 
Table 2. Number of grid disturbances recorded in February 2017 before integration.

\begin{tabular}{|c|c|c|c|c|c|}
\hline \multirow{2}{*}{$\begin{array}{l}\text { Nature of load } \\
\text { Shedding }\end{array}$} & \multicolumn{5}{|c|}{ Automatic load shedding } \\
\hline & $\begin{array}{l}\text { Manual } \\
\text { Shedding }\end{array}$ & $\begin{array}{l}\text { Shedding } \\
1^{\text {st }} \text { stage }\end{array}$ & $\begin{array}{l}\text { Shedding } \\
2^{\text {nd }} \text { stage }\end{array}$ & $\begin{array}{l}\text { Shedding } \\
3^{\text {rd }} \text { stage }\end{array}$ & $\begin{array}{l}\text { Shedding } \\
4^{\text {th }} \text { stage }\end{array}$ \\
\hline Number of Shedding & 0 & 13 & 0 & 0 & 0 \\
\hline Shedding Power of & $0 \mathrm{MW}$ & \multicolumn{4}{|c|}{$502.2 \mathrm{MW}$} \\
\hline
\end{tabular}

Table 3. Number of grid disturbances recorded in February 2018 after integration.

\begin{tabular}{|c|c|c|c|c|c|}
\hline \multirow{2}{*}{$\begin{array}{l}\text { Nature of load } \\
\text { Shedding }\end{array}$} & \multicolumn{5}{|c|}{ Automatic load shedding } \\
\hline & $\begin{array}{l}\text { Manual } \\
\text { Shedding }\end{array}$ & $\begin{array}{l}\text { Shedding } \\
1^{\text {st }} \text { stage }\end{array}$ & $\begin{array}{l}\text { Shedding } \\
2^{\text {nd }} \text { stage }\end{array}$ & $\begin{array}{l}\text { Shedding } \\
3^{\text {rd }} \text { stage }\end{array}$ & $\begin{array}{l}\text { Shedding } \\
4^{\text {th }} \text { stage }\end{array}$ \\
\hline Number of Shedding & 7 & 22 & 1 & 1 & 0 \\
\hline Shedding Power of & $48 \mathrm{MW}$ & \multicolumn{4}{|c|}{$955 \mathrm{MW}$} \\
\hline
\end{tabular}

was 502.2 MW while after the connection of those plants i.e. in February 2018, the frequency load shedding power was $1003 \mathrm{MW}$. Therefore, the presence of PV plants has led to an almost doubling of the frequency load shedding capacity by causing it three (3) times in February 2018. So, we clearly see the impact of $\mathrm{PV}$ power plants on power losses.

For the energy lost, by considering the first stage load shedding of "Table 1" on December 17th, 2017 which is one of the 2 highly perturbed days, we had:

\begin{tabular}{cccc}
\hline \multirow{2}{*}{ Type of load shedding } & \multicolumn{3}{c}{ Electrical shedding } \\
\cline { 2 - 4 } & Start time & End time & Power shed [MW] \\
\hline 1st stage & $12: 35$ & $12: 44$ & 52.8 \\
1st stage & $15: 44$ & $15: 46$ & 34.2 \\
1st stage & $15: 48$ & $16: 03$ & 38 \\
\hline
\end{tabular}

$$
\text { Energy }=\text { Power } * \text { Time }
$$

It lasted 9 minutes for the first (12:35 to 12:44) that should be converted in hours in the calculation of the energy.

$$
\text { Energy }=52.8 \mathrm{MW} *(9 \mathrm{~min} / 60 \mathrm{~min})=7.92 \mathrm{MWh}
$$

Then we have for the others, 2 minutes and 15 minutes, an energy loss of:

$$
\begin{aligned}
\text { Energy } & =34.2 \mathrm{MW} *(2 \mathrm{~min} / 60 \mathrm{~min})=1.14 \mathrm{MWh} \\
\text { Energy } & =38 \mathrm{MW} *(15 \mathrm{~min} / 60 \mathrm{~min})=9.5 \mathrm{MWh}
\end{aligned}
$$

Meaning that due to the frequency fluctuation on December $17^{\text {th }}, 2017$, an energy loss of $18.56 \mathrm{MWh}$ by automatic $1^{\text {st }}$ stage shedding occurred. Considering Table 3 also, for an automatic shedding of 955 MW over 28 days with approximately 6 hours of sun per day, we got around 160,440 MWh energy lost in one month on the Senegalese grid due to the integration of only 2 PV plants (Santhiou Mékhé and Tenmérina). 


\section{Conclusions}

In this work, we analyze operational data the Senegalese power supplier and from the PV power plants connected to that grid. Our study aims to highlight the influence of the integration of variable PV production on the grid frequency management. For this, remarkable days when we noticed instantaneous PV production and load sheddings in the power system have been considered. Our study brings out the link between the integration of instantaneous variable PV production and grid frequency variations which lead the load shedding. Indeed, the production of PV power plants depends on the irradiance while the irradiance is weather dependent. More load shedding was noticed in the integration of PV production. Thus, the intermittency which is a local problem at each PV power plant, becomes a variability problem at a system level for the whole national power grid. So, without a better frequency management system for the Senegalese grid, the renewable energies might cause on long term more harm to the populations and economic waste than improving the electric access.

This present work has to be extended by considering the eight (8) photovoltaic power plants currently being injected into the Senegalese power grid in order to highlight their impact on the grid frequency management. Regarding the intermittency of PV power plants, the implementation of storage capacities as a reliable solution for grid stability has to be investigated.

\section{Acknowledgements}

The authors express their deep gratitude to the national electricity supplier of Senegal (SENELEC) for the data used in this work.

\section{Conflicts of Interest}

The authors declare no conflicts of interest regarding the publication of this paper.

\section{References}

[1] Hernandez, J.C., Medina, A. and Jurado, F. (2008) Impact Comparison of PV System Integration into Rural and Urban Feeders. Energy Conversion and Management, 49, 1747-1765. https://doi.org/10.1016/j.enconman.2007.10.020

[2] ElNozahy, M.S. and Salama, M.M.A. (2013) Technical Impacts of Grid-Connected Photovoltaic Systems on Electrical Networks: A Review. Journal of Renewable Sustainable Energy, 5, 032702. https://doi.org/10.1063/1.4808264

[3] Ali, S., Pearsal, N. and Putrus, G. (2012) Impact of High Penetration Level of Grid-Connected Photovoltaic Systems on the UK Low Voltage Distribution Network. International Conference on Renewable Energies and Power Quality (ICREPQ'12), Santiago de Compostela, 28-30 March 2012, 519-522. https://doi.org/10.24084/repqj10.368

[4] Garba, M., Tankari, M.A. and Lefebvre, G. (2018) Methodology for Analyzing of a Grid Weakness and Resiliency Factors: Case of Niger National Grid. 7 th International Conference on Renewable Energy Research and Applications (ICRERA 
2018), Paris, 14-17 October 2018, 14-17. https://doi.org/10.1109/ICRERA.2018.8566870

[5] Guingane, T.T., Koalaga, Z., Boego, C., Simonguy, E., Ouiya, N., Bonkoungou, D. and Zougmore, F. (2017) Impact of Photovoltaic Penetration on the Electrical Network. American Journal of Innovative Research \& Applied Sciences, 5, 397-404.

[6] Guingane, T.T., Bonkoungou, D., Koalaga, Z. and Zougmore, F. (2017) Photovoltaic (PV) System Connected to the Grid without Battery Storage as a Solution to Electricity Problems Burkina Faso. International Journal of Engineering Research, 6, 30-33.

[7] Tan, Y.T. and Kirschen, D. (2007) Impact on the Power System of a Large Penetration of Photovoltaic Generation. 2007 IEEE Power Engineering Society General Meeting, Tampa, FL, 24-28 June 2007, 1-8. https://doi.org/10.1109/PES.2007.385563

[8] Blanket, F. (2013) Impact de l'intégration des EnR sur les reseaux de distribution d'électricité. Clubs Mines-Energie et Mines-Environnement et Développement Durable, ERDF.

[9] Krakowsky, V. (2016) Intégration du renouvelable et stratégies de déploiement du réseau électrique: Réconciliation d'échelles spatio-temporelles dans des exercices prospectifs de long terme. PhD Thesis, PSL Research University, Paris.

[10] Mulder, F.M. (2014) Implications of Diurnal and Seasonal Variations in Renewable Energy Generation for Large Scale Energy Storage. Journal of Renewable and Sustainable Energy, 6, 033105. https://doi.org/10.1063/1.4874845

[11] Onuka, S., Umemura, A., Takahashi, R., Tamura, J., Sakahara, A., Tosaka, F. and Nakamoto, R. (2020) Frequency Control of Power System with Renewable Power Sources by HVDC Interconnection Line and Battery Considering Energy Balancing. Journal of Power and Energy Engineering, 8, 11-24. https://doi.org/10.4236/jpee.2020.84002

[12] Guingane, T., Bonkoungou, D., Koalaga, Z. and Zougmoré, F. (2017) Photovoltaic (PV) System Connected to the Grid without Battery Storage as a Solution to Electricity Problems in Burkina Faso. International Journal of Engineering Research, 6, 30-33. 